\title{
Resistance of SMMC-7721 hepatoma cells to etoposide in hypoxia is reversed by VEGF inhibitor
}

\author{
SHANSHAN SHI ${ }^{1}$, CHENXING YUAN $^{1}$, KAIZAN ZHUANG $^{2}$, GUIKAI LIANG ${ }^{1}$, ZHANGTING YAO $^{1}$, \\ DUODUO WANG ${ }^{1}$, QINJIE WENG $^{1}$, JI CAO ${ }^{1}$, PEIHUA LUO $^{1}$, HONG ZHU $^{1}$, LING DING ${ }^{1}$ and SHENGLIN MA ${ }^{3,4}$ \\ ${ }^{1}$ Zhejiang Province Key Laboratory of Anti-Cancer Drug Research, Institute of Pharmacology and Toxicology, \\ College of Pharmaceutical Sciences, Zhejiang University, Hangzhou, Zhejiang 310058; ${ }^{2}$ Department of Pharmacy, \\ Fenghua Hospital, Ningbo, Zhejiang 315040; ${ }^{3}$ Department of Pharmacy, Hangzhou First People's Hospital, \\ Hangzhou, Zhejiang 310009; ${ }^{4}$ Department of Pharmacy, The Second Clinical Medical College, \\ Zhejiang Chinese Medical University, Hangzhou, Zhejiang 310053, P.R. China
}

Received January 12, 2014; Accepted October 24, 2014

DOI: $10.3892 / \mathrm{mmr} .2015 .3217$

\begin{abstract}
Hypoxia is associated with resistance to chemotherapy in a number of human cancer types; particularly in hepatocellular carcinoma (HCC), which is a highly vascularized tumor. To develop a potential combination therapy strategy that is capable of overcoming the hypoxia-induced insensitivity to chemotherapy, the HCC cell SMMC-7721 was employed to investigate the hypoxia-induced chemoresistance to etoposide. Increased levels of hypoxia-inducible factor- $1 \alpha$ (HIF-1 $\alpha)$ and vascular endothelial growth factor (VEGF) were observed when SMMC-7721 cells were exposed to hypoxia, and exposure of tumor cells to hypoxia impaired etoposide-induced DNA damage, as indicated by the failure of upregulation of $\gamma \mathrm{HA} 2 \mathrm{X}$. Etoposide-induced apoptosis and cell cycle arrest of SMMC-7721 was also impaired in hypoxia. However, co-treatment with anti-VEGF significantly restored etoposide-induced cell apoptosis and cell cycle arrest, as indicated by the elimination of B-cell lymphoma 2 (Bcl-2), procaspase 3, cyclin B1 and Cdc2. Furthermore, anti-VEGF
\end{abstract}

Correspondence to: Professor Ling Ding, Zhejiang Province Key Laboratory of Anti-Cancer Drug Research, Institute of Pharmacology and Toxicology, College of Pharmaceutical Sciences, Zhejiang University, 866 Yuhangtang Road, Hangzhou, Zhejiang 310058, P.R. China

E-mail:1d362@zju.edu.cn

Professor Shenglin Ma, Department of Pharmacy, Hangzhou First People's Hospital, 261 Huansha Road, Hangzhou, Zhejiang 310009, P.R. China

E-mail: mashenglin@medmail.com.cn

Abbreviations: HIF, hypoxia-inducible factor; VEGF, vascular endothelial growth factor; HCC, hepatocellular carcinoma; rhVEGF $_{165}$, recombinant human vascular endothelial growth factor (165); NF- $\mathrm{B}$, nuclear factor $\kappa \mathrm{B}$.

Key words: hypoxia, etoposide, resistance, HIF-1 $\alpha$, VEGF eliminated phosphorylation of AKT, ERK and $\mathrm{I} \kappa \mathrm{B}-\alpha$ resulting from hypoxia, suggesting the involvement of VEGF in the activation of the survival pathways. In conclusion, the present study suggests a significant role of VEGF in the chemoresistance of etoposide in hypoxia. A rational chemotherapy should be developed based on a combination of etoposide and anti-VEGF.

\section{Introduction}

The term hypoxia describes a reduction in the normal level of tissue oxygen tension, which may be acute or chronic. Hypoxia is the most notable and prevailing characteristic of the microenvironment of solid tumors (1). Consequently, adaptations to hypoxia are necessary for the survival of tumor cells in such microenvironments. Hypoxia-inducible factor-1 (HIF-1) is a transcriptional complex that is activated in response to hypoxia and other growth factors, and has a significant role in tumor progression, invasion and metastasis $(2,3)$. A pool of studies has provided evidence indicating that the overexpression of HIF-1 $\alpha$ subunit is associated with a poor prognostic outcome as well as resistance to chemotherapy and radiation (4-7). It is also well established that HIF-1 $\alpha$ regulates multiple proangiogenic factors, including vascular endothelial growth factor (VEGF). Hypoxia-induced VEGF may activate the MAPK-related VEGF receptor signaling pathway to elicit anti-apoptotic effects in a self-activating manner and induce angiogenesis primarily through its interaction with two tyrosine kinase receptors expressed in vascular endothelial cells, VEGFR1 (Flt1) and VEGFR2 (Flk1/KDR) (8). Furthermore, there is emerging evidence demonstrating that VEGF may also form an autocrine loop with HIF-1 $\alpha$, contributing to tumor cell survival as well as drug resistance during hypoxia in neuroblastoma, osteosarcoma, rhabdomyosarcoma and breast cancer cells (9-11). The anticancer effect of the pharmacological VEGF antagonism beyond interference with angiogenesis is therefore a significant area of cancer research.

Hypoxia and DNA damage occur simultaneously when therapies that cause DNA damage are applied to tumors bearing hypoxic regions. Cells may be eliminated following 
DNA damage through various forms of programmed death, including apoptosis, autophagy, mitotic catastrophe and necrosis. Among these, a common paradigm is that chemotherapeutic agents stimulate cells to undergo apoptosis, implying that impairment of apoptotic pathways may be involved in the development of chemoresistance (12).

Hepatocellular carcinoma (HCC) is one of the most common types of cancer and a leading cause of cancer-related mortality worldwide. As a highly vascularized tumor with poor prognosis, elevated levels of VEGF have been identified and a greater expression of VEGF has been associated with shorter survival in HCC patients (13-15). Therefore, inhibition of VEGF is an attractive target in HCC treatment (16). Significant clinical and biologic research into bevacizumab, a humanized monoclonal antibody that binds VEGF prior to its attachment to its natural receptors, has been undertaken with regard to $\mathrm{HCC}$, since systemic therapy with cytotoxic agents has demonstrated a notable benefit (17-19).

Given the potential roles of chemotherapeutic agents and VEGF antagonism in cancer therapeutics, one rational strategy would be to combine anti-VEGF treatment with DNA damage agents such as etoposide. We used the SMMC-7721 hepatoma cell line in the present study, which is an identified chemoresistant phenotype when subjected to hypoxia, with elevated serum VEGF levels contributing to tumor growth and metastasis. This study investigates the role of this combination strategy and provides evidence that pre-exposure of SMMC-7721 cells to hypoxia weakens etoposide-induced cytotoxicity. Notably, the anti-VEGF strategy facilitated DNA damage ability of etoposide followed by cell cycle delay and apoptosis induction, which served to overcome hypoxia-driven etoposide resistance.

\section{Materials and methods}

Reagents and antibodies. Etoposide was purchased from Sigma-Aldrich (St. Louis, MO, USA); a stock solution of $100 \mathrm{mM}$ was prepared with dimethyl sulfoxide and stored at $-20^{\circ} \mathrm{C}$. The stock solution was further diluted with the appropriate medium immediately prior to use. The antibodies to HIF-1 $\alpha$ and Flt1 (VEGFR1) were purchased from Calbiochem (La Jolla, CA, USA) and R\&D systems (Minneapolis, MN, USA), respectively. The antibodies to VEGF, p53, Bcl-2, Bax, procaspase 3, cyclin A, cyclin B1, cdc2, AKT, ERK, $\alpha$-tubulin and $\beta$-actin, as well as HRP-labeled secondary anti-goat, anti-mouse and anti-rabbit antibodies were purchased from Santa Cruz Biotechnology, Inc. (Dallas, TX, USA). The antibodies to $\gamma \mathrm{H} 2 \mathrm{AX}$, p-AKT (Ser473), p-ERK, p-IкB- $\alpha$ (Ser32) and GAPDH were obtained from Cell Signaling Technology, Inc. (Beverly, MA, USA). Recombinant human $\mathrm{VEGF}_{165}$ $\left(\mathrm{rhVEGF}_{165}\right)$ and a neutralizing antibody against VEGF (anti-mouse monoclonal antibody) were purchased from R\&D Systems.

Cell culture and establishment of hypoxia culture conditions. Human HCC SMMC-7721 cells (Shanghai Institute of Biological Sciences, Shanghai, China) were cultured in RPMI-1640 (Invitrogen Life Technologies, Carlsbad, CA, USA) supplemented with $10 \%$ fetal bovine serum containing $100 \mathrm{U} / \mathrm{ml}$ penicillin and $100 \mu \mathrm{g} / \mathrm{ml}$ streptomycin
(Sigma-Aldrich). The cells were kept in a humidified atmosphere of $5 \% \mathrm{CO}_{2}$ and $20 \% \mathrm{O}_{2}$ at $37^{\circ} \mathrm{C}$. Environmental hypoxic conditions $\left(0.6 \% \mathrm{O}_{2}\right)$ were achieved in an airtight humidified chamber continuously flushed with a mixed gas where $\mathrm{N}_{2}$ was used to compensate for the reduced $\mathrm{O}_{2}$ level.

Cytotoxicity assay. Cell proliferation was determined by a standard 3-[4,5-dimethylthia-zol-2-yl]-2,5-diphenyltetrazolium bromide (MTT) assay. Cells were seeded in 96-well plates, and hypoxic cells were allowed to attach for one day before exposure to etoposide at concentrations specified or vehicle control alone. Plates were assayed 48 and $72 \mathrm{~h}$ after the initiation of the designated treatment. All experiments were repeated three times.

Flow cytometric determination of cell cycle. To determine the phase distribution of the DNA content, propidium iodide (PI) staining was performed. Following the designated treatment of actively proliferating cultures, cells were collected and washed twice with phosphate-buffered saline (PBS) buffer and fixed in $70 \%$ ice-cold ethanol overnight. The cell pellet was re-suspended in PBS plus $0.5 \mathrm{mg} / \mathrm{ml} \mathrm{RNaseA}$ at $37^{\circ} \mathrm{C}$ for $30 \mathrm{~min}$ prior to staining with $5 \mathrm{mg} / \mathrm{ml} \mathrm{PI} \mathrm{(Sigma-Aldrich)}$ at room temperature in the dark for another $30 \mathrm{~min}$. The analysis was performed with a FACScan flow cytometer (BD Biosciences, San Jose, CA, USA).

Flow cytometric determination of apoptosis. Cells were collected and washed twice with ice-cold PBS buffer following the designated treatment of actively proliferating cultures. Subsequently, cells were stained with annexin V-fluorescein and PI according to the descriptions in the commercial apoptosis detection kit (BD Pharmingen, San Diego, CA, USA). Analysis was performed with a FACScan flow cytometer (BD Biosciences).

Protein expression. Proteins were extracted in radioimmunoprecipitation assay buffer $(150 \mathrm{mM} \mathrm{NaCl}, 50 \mathrm{mM}$ Tris, $2 \mathrm{mM}$ EGTA, 2 mM EDTA, $25 \mathrm{~mm} \mathrm{NaF}, 25 \mathrm{~mm}$ glycerophosphate, $0.2 \%$ Triton X-100, 0.3\% NONIDET P-40 and 0.1 mM PMSF). Total protein concentrations of whole cell lysates were determined using the Bio-Rad reagent (Bio-Rad, Hercules, CA, USA) bicinchoninic acid method. Equal amounts of $40 \mu \mathrm{g}$ total protein were loaded per lane. Proteins were fractionated on $8-12 \%$ Tris-Glycine pre-cast gels (Novex, San Diego, CA, USA), transferred to Immobilon-P transfer membrane (Millipore, Billerica, MA, USA), and probed with primary antibodies and then HRP-labeled secondary antibodies. Proteins were visualized using ECL western blotting detection reagents (Amersham Biosciences, Piscataway, NJ, USA).

\section{Results}

Hypoxia impairs etoposide-induced cytotoxicity. To examine the effect of hypoxia, SMMC-7721 cells were exposed to normoxia or hypoxia $\left(0.6 \% \mathrm{O}_{2}\right)$, respectively, in the presence of serum to avoid glucose deprivation or cell cycle inhibition. It was noted that etoposide exerted significant concentrationand time-dependent cytotoxicity in a normoxic atmosphere, as shown in Fig. 1A. Conversely, an impaired anti-proliferative 

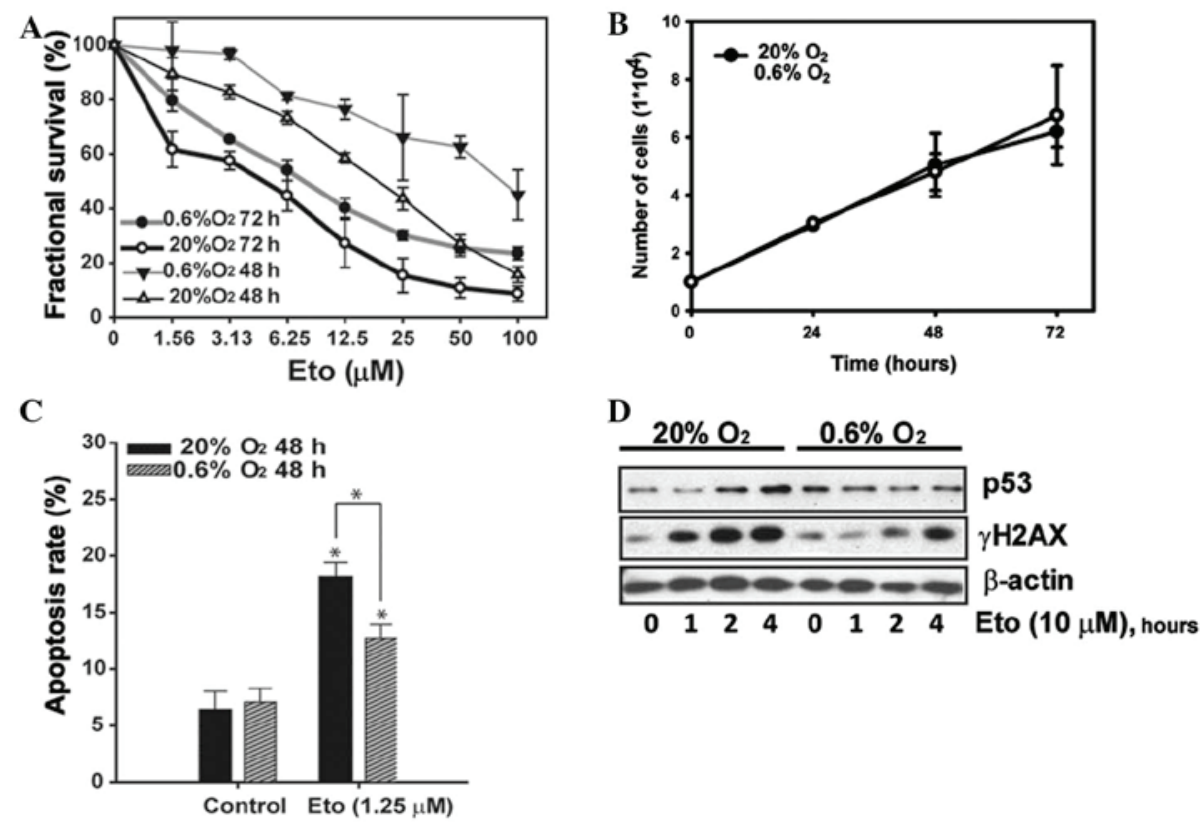

Figure 1. Hypoxia-induced etoposide resistance in SMMC-7721 cells. (A) Hypoxia impairs etoposide-induced anti-proliferative ability in SMMC-7721 cells. Cells were exposed to various concentrations of etoposide for 48 or $72 \mathrm{~h}$ under normoxia or hypoxia followed by MTT assay. (B) Growth curves of SMMC-7721 cells under normoxia and hypoxia. Cells were seeded in 24 -well plates in duplicate wells and were trypsinized and manually counted every day. The data were normalized by setting the value at day 0. (C) SMMC-7721 cells were administered etoposide for $48 \mathrm{~h}$, then collected for apoptosis analyses by flow cytometry. (D) Hypoxia impairs etoposide-induced DNA damage ability in SMMC-7721 cells. Cells were treated with etoposide (10 $\mu \mathrm{M})$ for $0-4 \mathrm{~h}$ before they were collected for $\mathrm{p} 53$ and $\gamma \mathrm{H} 2 \mathrm{AX}$ detection. Data are presented as the means \pm standard deviation $(\mathrm{n}=3)$. The statistical significance of cell cycle and apoptosis results was analyzed using a two-sided Student's t-test; ${ }^{*} \mathrm{P}<0.01$. Eto, etoposide.

effect was observed under the hypoxic environment. To exclude the possibility that the diminished cytotoxicity of etoposide was due to a general anti-proliferative effect of hypoxic conditions that render more slowly cycling cells, cell growth curves were analyzed under various oxygen conditions, as shown in Fig. 1B, to demonstrate that hypoxia alone did not lower cell proliferation within $72 \mathrm{~h}$. However, the etoposide-induced apoptosis was significantly reduced (Fig. 1C).

Etoposide is known to stabilize the cleavable complex formed between topoisomerase II and DNA, and subsequently form strand breakage. The topoisomerase II inhibitor causes replication stress and generates the dominant damage-induced phosphorylation of the minor histone $\mathrm{H} 2 \mathrm{~A}(\gamma \mathrm{H} 2 \mathrm{AX})$, which has become one of the most widely used measures of DNA damage and is observed within a short-term exposure to etoposide (20). We treated SMMC-7721 cells for 0-4 h with a relatively high concentration $(10 \mu \mathrm{M})$ and then measured the $\gamma \mathrm{H} 2 \mathrm{AX}$ level. The western blotting results shown in Fig. 1D reveal that a significant increase of $\gamma \mathrm{H} 2 \mathrm{AX}$ was observed after $1 \mathrm{~h}$ of etoposide treatment, which reached a platform at $4 \mathrm{~h}$. Since p53 was reported to be involved in apoptosis in response to DNA damage, p53 accumulation was also analyzed (21). A significant accumulation of p53 was detected following a $2 \mathrm{~h}$ challenge of etoposide. However, far less significant expression of $\gamma \mathrm{H} 2 \mathrm{AX}$ and p53 was observed in hypoxia (Fig. 1D).

Anti-VEGF intervention improves etoposide-induced apoptosis in hypoxia. By culturing SMMC-7721 cells under hypoxic conditions, increased levels of HIF-1 $\alpha$ and VEGF were observed (Fig. 2A). To investigate the effect of VEGF in hypoxia-induced chemoresistance to etoposide, we exposed
SMMC-7721 cells to etoposide with or without anti-VEGF under hypoxia and further detected the apoptosis. As expected, VEGF interference increased the apoptotic fraction (Fig. 2B).

To demonstrate how this combination strategy might affect etoposide function in DNA damage under hypoxia, SMMC-7721 cells were treated with or without anti-VEGF upon etoposide administration $(10 \mu \mathrm{M})$. Combined treatment of anti-VEGF and etoposide significantly upregulated $\gamma \mathrm{H} 2 \mathrm{AX}$ and p53 levels, to a level similar to that observed with a single treatment of etoposide in normoxia (Fig. 2C).

Mitochondria play a pivotal role in the regulation of apoptosis by regulating the balance between anti-apoptotic family members including Bcl-2 and pro-apoptotic family members including Bax. To determine whether the downstream activators of apoptosis were induced, we analyzed the expression of $\mathrm{Bcl}-2$, Bax and procaspase 3. A significant increase in Bax as well as significant decreases in Bcl-2 and procaspase 3 were observed upon etoposide treatment in normoxic conditions (Fig. 2D). However, the expression of these proteins was not significantly affected by etoposide alone in hypoxia, while the anti-VEGF combination helped to further downregulate Bcl-2 and procaspase 3 , which was consistent with apoptosis data (Fig. 2B). Taken together, the anti-VEGF combination strategy may affect mitochondrial-related apoptosis and improve etoposide-induced SMMC-7721 apoptosis under hypoxia.

Anti-VEGF facilitates etoposide-induced cell cycle arrest under hypoxia. Hypoxia is also reported to induce cell cycle arrest in certain tumors, leading to chemo- and/or radio-resistance (22). SMMC-7721 cells were treated with various concentrations of etoposide for $48 \mathrm{~h}$ before analyses of cell 


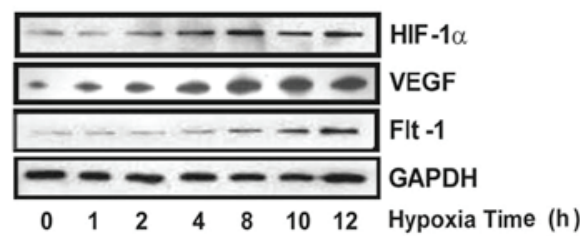

B
N:

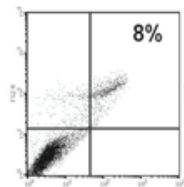

Control

H:

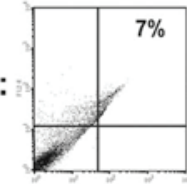

Control

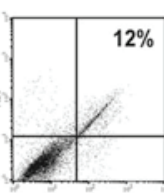

1.25 $\mu \mathrm{M}$ Eto
C

D

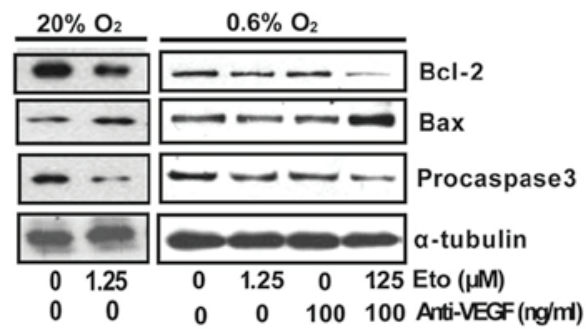

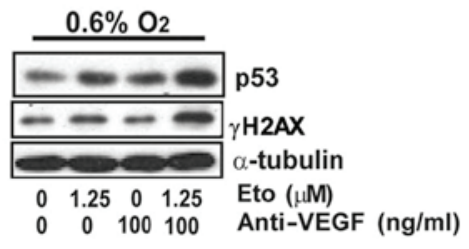

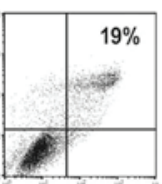

$1.25 \mu \mathrm{M}$ Eto

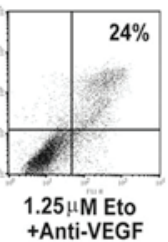

Figure 2. Anti-vascular endothelial growth factor (VEGF) intervention improves etoposide-induced apoptosis in hypoxia. (A) Cells were exposed to hypoxia for $0-12 \mathrm{~h}$ and the lysates were immunoblotted against hypoxiainducible factor- $1 \alpha$ (HIF-1 $\alpha)$, VEGF and Flt1 antibody. (B) Cells were treated with etoposide alone in normoxia or treated with both anti-VEGF antibody and etoposide in hypoxia, and apoptosis was analyzed after $48 \mathrm{~h}$ exposure. (C) Cells were incubated with anti-VEGF for $24 \mathrm{~h}$ followed by an additional exposure to etoposide $(1.25 \mu \mathrm{M})$ for $4 \mathrm{~h}$ under hypoxic conditions. Cells were then harvested, extracted and subjected to immunoblotting for $\gamma \mathrm{H} 2 \mathrm{AX}$ and p53 expression. (D) Cells were incubated with anti-VEGF for $24 \mathrm{~h}$ and then treated with etoposide for $24 \mathrm{~h}$ before they were collected for Bcl-2, Bax and procaspase 3 analysis. Eto, etoposide.

cycle phase distribution were performed. Hypoxia alone did not appear to induce cell cycle arrest since there were no notable differences between the hypoxic and normoxic cells. Etoposide exhibited a concentration-dependent effect in G2/M arrest (data not shown here). As shown in Fig. 3A, 48-h treatment of single etoposide $(1.25 \mu \mathrm{M})$ triggered the arrest of $87.3 \pm 3.5 \%$ cells (control, $10.5 \pm 1.7 \%$ ) in the $\mathrm{G} 2 / \mathrm{M}$ phase under normoxic conditions. In contrast, a rate of only $64.1 \pm 7.7 \%$ (control, $12.4 \pm 5.3 \%$ ) was observed under hypoxia. However, an increased proportion of G2/M phase arrested cells was observed when cells were treated with both anti-VEGF and etoposide, suggesting that VEGF reduced etoposide in cell cycle arrest (Fig. 3B).

Next, we assessed the effects of etoposide alone or combined with anti-VEGF on cell cycle regulating proteins. In
$\mathbf{A}$

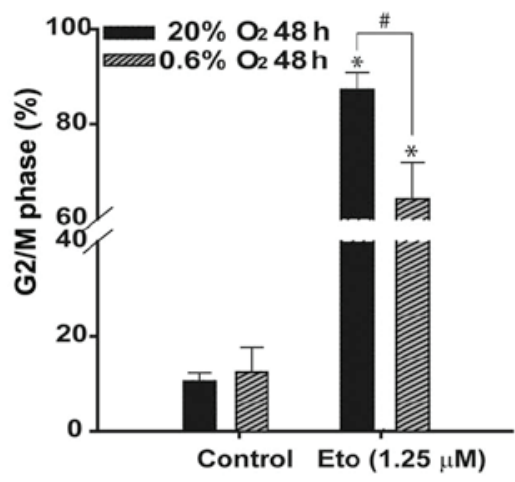

B
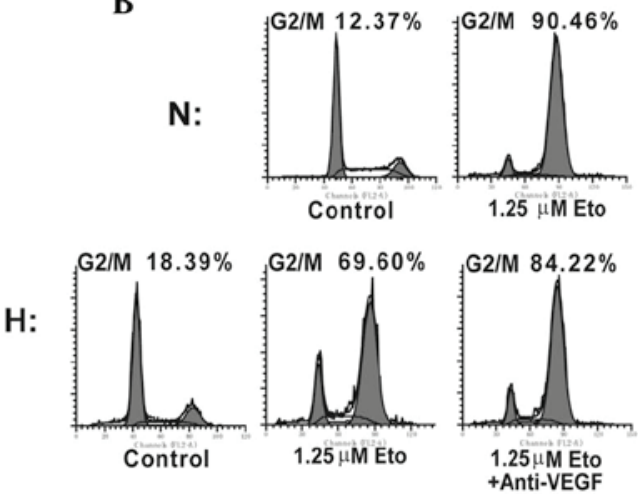

C

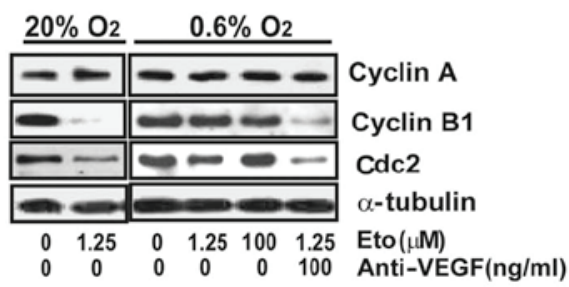

Figure 3. Anti-vascular endothelial growth factor (VEGF) facilitates etoposide-induced cell cycle arrest under hypoxia. (A) SMMC-7721 cells were treated with etoposide for $48 \mathrm{~h}$ then underwent cell cycle analysis by flow cytometry. (B) SMMC-7721 cells pre-incubated with anti-VEGF for $24 \mathrm{~h}$ followed by etoposide exposure for $48 \mathrm{~h}$ were collected for cell cycle analyses by flow cytometry. $\mathrm{N}$, normoxia; $\mathrm{H}$, hypoxia. Results from a representative experiment are presented. (C) G2/M phase-related proteins cyclin B1, cdc2, p-cdc2 (Thr161) and $\alpha$-tubulin were assessed by western blotting as described in Fig. 2B. ${ }^{*} \mathrm{P}<0.01 ;{ }^{\#} \mathrm{P}<0.05$. Eto, etoposide.

normoxia, challenge with etoposide alone resulted in a significant decrease in cyclin B1 and Cdc2 (Fig. 3C). However, in hypoxia, etoposide only caused a slight decrease in cyclin B1 and Cdc2. Significant downregulation of cyclin B1 and Cdc2 was observed when the cells were co-treated with etoposide and anti-VEGF, which was similar to that observed under normoxia.

Anti-VEGF combination strategy is correlated with the AKT, ERK and nuclear factor- $\kappa B(N F-\kappa B)$ pathway. Current studies suggest that the AKT and ERK pathways are the most relevant survival pathways in tumor cells (23). We thus assessed whether or not AKT and ERK play a role in hypoxia-induced insensitivity to etoposide in SMMC-7721 cells. As shown in Fig. 4, hypoxia triggered phosphorylation of AKT and ERK. Administration of etoposide alone resulted in a slight decrease 


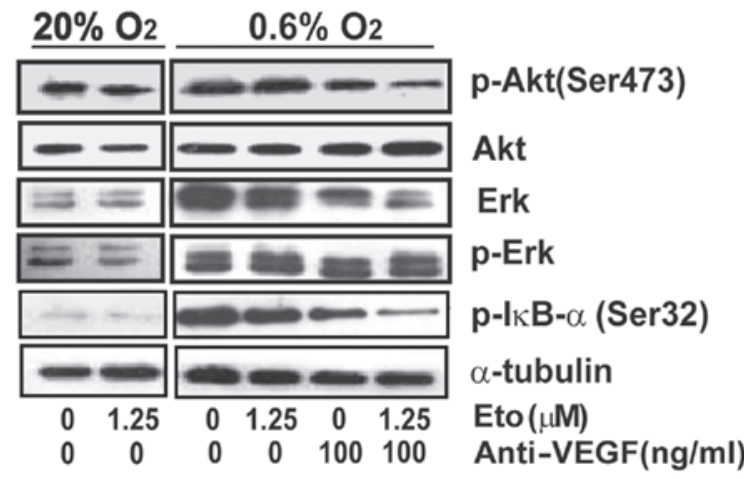

Figure 4. Nuclear factor- $\kappa \mathrm{B}(\mathrm{NF}-\kappa \mathrm{B})$ but not AKT or ERK is involved in overcoming hypoxia resistance by anti-vascular endothelial growth factor (VEGF) combination strategy. Cells were treated as in Fig. 3; cell lysates were immunoblotted for AKT, p-AKT, ERK, p-ERK and p-IкB- $\alpha$ (Ser32) using corresponding antibodies. Eto, etoposide.

in the phosphorylation of AKT and ERK. However, anti-VEGF alone or the combination treatment completely eliminated the phosphorylation of these proteins, suggesting that the AKT and ERK pathways are involved in anti-VEGF-restored sensitivity to etoposide.

The transcription factor $\mathrm{NF}-\kappa \mathrm{B}$ has been implicated in resistance to chemotherapeutic treatment. Recent evidence has demonstrated significant cross-talk and the inter-independence of NF- $\kappa \mathrm{B}$ and HIF-1 $\alpha$ signaling $(24,25) . N F-\kappa B$ is a transcriptional activator of HIF-1 $\alpha$ and, conversely, HIF-1 $\alpha$ accumulation is shown to promote NF- $\kappa \mathrm{B}$. Since phosphorylation of $\mathrm{I} \kappa \mathrm{B}-\alpha$ at Ser32 is essential for the release of active $\mathrm{NF}-\kappa \mathrm{B}$, phosphorylation at this site is a significant marker of $\mathrm{NF}-\kappa \mathrm{B}$ activation $(26,27)$. Here, we demonstrate that phosphorylation of $\mathrm{I} \kappa \mathrm{B}-\alpha$ at Ser32 was induced by hypoxia which was eliminated by VEGF inhibition, suggesting the involvement of $\mathrm{NF}-\kappa \mathrm{B}$.

\section{Discussion}

Hypoxia-induced chemoresistance is an aspect of tumor biology that has received increasing attention over the last decades, with the characterization of HIFs being of particular significance $(29,30)$. Genetic approaches and small-molecule inhibitors targeting HIF-1 have proven effective in decreasing hypoxia-induced resistance to chemotherapeutics in tumors $(31,32)$. Previous studies suggest that VEGF/Flt1 may also form an autocrine loop with HIF-1 $\alpha$, which contributes to cell survival and drug resistance during hypoxia (9-11). Although KDR is generally considered to be the major mediator of the mitogenic and angiogenic effects of VEGF (33), emerging studies demonstrate that Flt1 is present and functional in a diverse group of tumors. In addition, Flt1 is the only receptor associated with VEGF that contains a binding site for HIF-1 $\alpha$, which further supports the recruitment of the VEGF/Flt1 system in HIF-1 $\alpha$-driven tumor progression. Bevacizumab has been shown to improve treatment outcomes in selected patients with advanced colorectal, breast and non-small cell lung cancer. However, it is also being evaluated among patients with earlier-stage cancer, and among patients with other types of cancer. The results of a phase II clinical trial $(18,19)$ revealed that the combination of two targeted therapies, bevacizumab and erlotinib, exhibited anticancer activity in patients with advanced HCC and is therefore worthy of further study.

The DNA damaging reagent etoposide has been demonstrated to induce apoptosis in a variety of tumor cell lines harboring either wild-type or mutant p53. Although the signaling pathways mediating etoposide-induced apoptosis are unclear, one pathway may involve p53 since DNA damage induced by etoposide has been shown to activate p53. It is also known that $\mathrm{p} 53$ protein is a potent negative regulator of HIF-1 $\alpha$ and VEGF in hypoxia. p53 represses VEGF during hypoxia by binding the transcription factor SP1 and inhibiting its ability to bind the VEGF promoter (34). HIF-1 $\alpha$ activity may also be inhibited by p53, which directly binds HIF-1 $\alpha$ and targets protein for degradation and thereby downregulated VEGF transcription $(35,36)$. In addition, the ability of p53 to inhibit the HIF system is mediated by its physical interaction with $\mathrm{HIF}-1 \alpha$ and does not even require its transcriptional activity. Using $\gamma \mathrm{H} 2 \mathrm{AX}$ as an indicator of DNA damage, we observed that hypoxia weakened etoposide-induced DNA damage. Notably, the anti-VEGF combination strategy enhanced $\gamma \mathrm{H} 2 \mathrm{AX}$ and p53 expression. Subsequently, cell cycle and apoptosis data suggested that the anti-VEGF combination with etoposide could also restore etoposide function to a level comparable with that observed in normoxia.

Previous studies have shown indirect links between HIF- $1 \alpha$ and NF- $\kappa$ B transcription pathways (37). The inactive $N F-\kappa B$ is primarily localized in the cytoplasm, and its activation involves its release from $\mathrm{I} \kappa \mathrm{B}-\alpha$ and translocation to the nucleus. This phosphorylation induces the degradation of I $\kappa$ B- $\alpha$ by the ubiquitin-proteasome system and the release of $N F-\kappa B$ for nuclear translocation. Preventing $N F-\kappa B$ activation exerts a tumor-suppressive effect by promoting apoptosis of transformed cells which would otherwise have given rise to cancer. In addition, $\mathrm{NF}-\kappa \mathrm{B}$ is a transcriptional activator of HIF- $1 \alpha$, and basal $N F-\kappa B$ activity is required for HIF-1 $\alpha$ accumulation in normoxia and during hypoxia. Previous studies have demonstrated significant cross-talk and the inter-independence of NF- $\mathrm{NB}$ and HIF-1 $\alpha$ signaling, indicating that $\mathrm{NF}-\kappa \mathrm{B}$ is a transcriptional activator of HIF-1 $\alpha$ and, conversely, HIF-1 $\alpha$ accumulation is shown to promote $\mathrm{NF}-\kappa \mathrm{B}(24,25)$. Furthermore, in vitro and in vivo studies have already shown that targeted inhibition of $N F-\kappa B$ sensitizes tumor cells to chemotherapy and radiation (38).

In this study, we combined etoposide, a commonly used chemotherapeutic agent, with monoclonal VEGF antibody to evaluate its role in hypoxia-induced resistance in hepatoma SMMC-7721 cells. The results revealed that hypoxia impaired etoposide function in DNA damage and resultant cell death and resulted in drug resistance. In addition, interference of VEGF inhibited hypoxia induction of HIF-1 $\alpha$. The anti-VEGF combination treatment enhanced etoposide efficacy by the attenuation of DNA damage followed by limited cell cycle delay and/or apoptosis and reversed drug resistance in SMMC-7721 cells.

\section{Acknowledgements}

This study was supported by National Natural Science Funds (no. 81273535 and no. 81272611) and Hangzhou Core Scientific 
research innovation project (no. 20112313A01). It also received support from the National Natural Science Foundation of China (81072657 and 91029745), Zhejiang Provincial Natural Science Foundation of China (Z2090053) and the Program for New Century Excellent Talents of the Ministry of Education of China.

\section{References}

1. Höckel M and Vaupel P: Tumor hypoxia: definitions and current clinical, biologic, and molecular aspects. J Natl Cancer Inst 93: 266-276, 2001.

2. Carroll VA and Ashcroft M: Role of hypoxia-inducible factor (HIF)-1alpha versus HIF-2alpha in the regulation of HIF target genes in response to hypoxia, insulin-like growth factor-I, or loss of von Hippel-Lindau function: implications for targeting the HIF pathway. Cancer Res 66: 6264-6270, 2006.

3. Semenza GL, Shimoda LA and Prabhakar NR: Regulation of gene expression by HIF-1. Novartis Found Symp 272: 33-36, 2006.

4. Schnitzer SE, Weigert A, Zhou J, et al: Hypoxia enhances sphingosine kinase 2 activity and provokes sphingosine-1phosphate-mediated chemoresistance in A549 lung cancer cells. Mol Cancer Res 7: 393-401, 2009.

5. Yang B, Fan L, Fang L, et al: Hypoxia-mediated fenretinide (4-HPR) resistance in childhood acute lymphoblastic leukemia cells. Cancer Chemother Pharmacol 58: 540-546, 2006.

6. Flamant L, Notte A, Ninane N, et al: Anti-apoptotic role of HIF-1 and AP-1 in paclitaxel exposed breast cancer cells under hypoxia. Mol Cancer 9: 191, 2010.

7. Sermeus A, Cosse JP, Crespin M, et al: Hypoxia induces protection against etoposide-induced apoptosis: molecular profiling of changes in gene expression and transcription factor activity. Mol Cancer 7: 27-31, 2008.

8. Wang D, Weng Q, Zhang L, et al: VEGF and Bcl-2 interact via MAPKs signaling pathway in the response to hypoxia in neuroblastoma. Cell Mol Neurobiol 29: 391-401, 2009.

9. Das B, Yeger H, Tsuchida R, et al: A hypoxia-driven vascular endothelial growth factor/Flt1 autocrine loop interacts with hypoxia-inducible factor-1alpha through mitogen-activated protein kinase/extracellular signal-regulated kinase $1 / 2$ pathway in neuroblastoma. Cancer Res 65: 7267-7275, 2005.

10. Tsuchida R, Das B, Yeger H, et al: Cisplatin treatment increases survival and expansion of a highly tumorigenic side-population fraction by upregulating VEGF/Flt1 autocrine signaling. Oncogene 27: 3923-3934, 2008.

11. Lee TH, Seng S, Sekine M, et al: Vascular endothelial growth factor mediates intracrine survival in human breast carcinoma cells through internally expressed VEGFR1/FLT1. PLoS Med 4: 186-191, 2007

12. Erler JT, Cawthorne CJ, Williams KJ, et al: Hypoxia-mediated down-regulation of Bid and Bax in tumors occurs via hypoxia-inducible factor 1-dependent and -independent mechanisms and contributes to drug resistance. Mol Cell Biol 24: 2875-2889, 2004.

13. Jeng KS, Sheen IS, Wang YC, et al: Prognostic significance of preoperative circulating vascular endothelial growth factor messenger RNA expression in resectable hepatocellular carcinoma: a prospective study. World J Gastroenterol 10: 643-648, 2004.

14. Jinno K, Tanimizu M, Hyodo I, et al: Circulating vascular endothelial growth factor (VEGF) is a possible tumor marker for metastasis in human hepatocellular carcinoma. J Gastroenterol 33: 376-382, 1998.

15. Kwak BK, Shim HJ, Park ES, et al: Hepatocellular carcinoma: correlation between vascular endothelial growth factor level and degree of enhancement by multiphase contrast-enhanced computed tomography. Invest Radiol 36: 487-492, 2001.

16. Pang R and Poon RT: Angiogenesis and antiangiogenic therapy in hepatocellular carcinoma. Cancer Lett 242: 151-167, 2006.
17. Sun W, Sohal D, Haller DG, et al: Phase 2 trial of bevacizumab, capecitabine, and oxaliplatin in treatment of advanced hepatocellular carcinoma. Cancer 117: 3187-3192, 2011

18. Thomas MB, Morris JS, Chadha R, et al: Phase II trial of the combination of bevacizumab and erlotinib in patients who have advanced hepatocellular carcinoma. J Clin Oncol 27: 843-850, 2009.

19. Kaseb AO, Garrett-Mayer E, Morris JS, et al: Efficacy of bevacizumab plus erlotinib for advanced hepatocellular carcinoma and predictors of outcome: final results of a phase II trial. Oncology 82: 67-74, 2012.

20. Smart DJ, Halicka HD, Schmuck G, et al: Assessment of DNA double-strand breaks and gammaH2AX induced by the topoisomerase II poisons etoposide and mitoxantrone. Mutat Res 641: 43-47, 2008.

21. Brady CA, Jiang D, Mello SS, et al: Distinct p53 transcriptional programs dictate acute DNA-damage responses and tumor suppression. Cell 145: 571-583, 2011.

22. Richard S, Geneviève CP, Lisa JF, et al: hypoxia-inducible factor-1 activity associated with decreased senescence and requires hypoxia-inducible factor-1 activity. Mol Cancer Ther 7: 1961-1973, 2008.

23. Pommier Y, Sordet O, Antony S, et al: Apoptosis defects and chemotherapy resistance: molecular interaction maps and networks. Oncogene 23: 2934-2949, 2004.

24. Jung Y, Isaacs JS, Lee S, et al: Hypoxia-inducible factor induction by tumour necrosis factor in normoxic cells requires receptor-interacting protein-dependent nuclear factor kappa B activation. Biochem J 370: 1011-1017, 2003.

25. Rius J, Guma M, Schachtrup C, et al: NF-kappaB links innate immunity to the hypoxic response through transcriptional regulation of HIF-1alpha. Nature 453: 807-811, 2008.

26. Perkins ND: Post-translational modifications regulating the activity and function of the nuclear factor kappa B pathway. Oncogene 25: 6717-6730, 2006.

27. Perkins ND and Gilmore TD: Good cop, bad cop: the different faces of NF-kappaB. Cell Death Differ 13: 759-772, 2006.

28. Cummins EP, Berra E, Comerford KM, et al: Prolyl hydroxylase-1 negatively regulates IkappaB kinase-beta, giving insight into hypoxia-induced NFkappaB activity. Proc Natl Acad Sci USA 103: 18154-18159, 2006.

29. Unruh A, Ressel A, Mohamed HG, et al: The hypoxia-inducible factor- 1 alpha is a negative factor for tumor therapy. Oncogene 22 : 3213-3220, 2003

30. Le QT, Denko NC and Giaccia AJ: Hypoxic gene expression and metastasis. Cancer Metastasis Rev 23: 293-310, 2004.

31. Sullivan R and Graham CH: Hypoxia prevents etoposide-induced DNA damage in cancer cells through a mechanism involving hypoxia-inducible factor 1. Mol Cancer Ther 8: 1702-1713, 2009.

32. Rohwer N, Dame C, Haugstetter A, et al: Hypoxia-inducible factor lalpha determines gastric cancer chemosensitivity via modulation of p53 and NF-kappaB. PLoS One 5: 12038, 2010.

33. Ferrara N: Vascular endothelial growth factor: basic science and clinical progress. Endocrine Rev 25: 581-611, 2004.

34. Pal S, Datta K and Mukhopadhyay D: Central role of p53 on regulation of vascular permeability factor/vascular endothelial growth factor (VPF/VEGF) expression in mammary carcinoma. Cancer Res 61: 6952-6957, 2001.

35. Ravi R, Mookerjee B, Bhujwalla ZM, et al: Regulation of tumor angiogenesis by p53-induced degradation of hypoxia-inducible factor 1alpha. Genes Dev 14: 34-44, 2000.

36. Yang J, Ahmed A, Poon E, et al: Small-molecule activation of p53 blocks hypoxia-inducible factor 1alpha and vascular endothelial growth factor expression in vivo and leads to tumor cell apoptosis in normoxia and hypoxia. Mol Cell Biol 29: 2243-2253, 2009.

37. Walmsley SR, Print C, Farahi N, et al: Hypoxia-induced neutrophil survival is mediated by HIF-1alpha-dependent NF-kappaB activity. J Exp Med 201: 105-115, 2005.

38. Wang C Y, Cusack J C, Liu R, et al: Control of inducible chemoresistance: enhanced anti-tumor therapy through increased apoptosis by inhibition of NF-кB. Nat Med 5: 412-417, 1999. 